\title{
Structurally simple synthetic 1, 4- disubstituted piperidines with high selectivity for resistant Plasmodium falciparum
}

Moses N. Ngemenya ${ }^{1,2^{*}}$ (D), Grace Ntube Abwenzoh ${ }^{2}$, Hermia Nalova Ikome ${ }^{3}$, Denis Zofou ${ }^{1,2}$, Fidele Ntie-Kang ${ }^{3}$ and Simon M. N. Efange ${ }^{3^{*}}$

\begin{abstract}
Background: Emergence of resistance to artemisinins and some of their combinations in chemotherapy of clinical malaria has intensified the search for novel safe efficacious antimalarial molecules. Fourteen synthetic 1, 4-disubstituted piperidines with simple molecular structures were evaluated in this study.

Methods: Antiplasmodial activity were determined against cultured chloroquine-sensitive 3D7 and resistant Dd2 strains of $P$. falciparum by in vitro parasite growth inhibition. A primary screen was done to identify active compounds by fluorescence microscopy followed by a secondary screen to determine $I C_{50}$ and $I C_{90}$ values of active compounds by the parasite lactate dehydrogenase assay. Cytotoxicity of active compounds was assessed using the MTT/formazan assay and selectivity indices (SIs) determined. Optical densities were analysed to obtain experimental results.

Results: The compounds produced 56 to $93 \%$ inhibition of parasite growth at $40 \mu \mathrm{g} / \mathrm{mL}$. Eight compounds (2 ketone, 5 alcohol and one amine analogues) showed high activity ( $\left(\mathrm{C}_{50} \mathrm{~s}\right.$ between 1 and $\left.5 \mu \mathrm{g} / \mathrm{mL}\right)$. Nine compounds were highly selective for the parasite (Sls $=15$ to 182). Three promising (alcohol) analogues were identified: [1-(4-fluorobenzyl) piperidin4-yl] [4-fluorophenyl] methanol, (7), [1-(3, 4-dichlorobenzyl) piperidin-4-yl] [4- fluorophenyl] methanol (8) and [1-(4-bromobenzyl) piperidin-4-yl] [4- fluorophenyl] methanol (11) which were more active on the resistant strain $\left(I C_{50}\right.$ values between 1.03 to $\left.2.52 \mu \mathrm{g} / \mathrm{mL}\right)$, than the sensitive strain $\left(I C_{50}\right.$ values between 2.51 to 4 . $43 \mu \mathrm{g} / \mathrm{mL})$.

Conclusions: The alcohol analogues were the most active and most selective for the parasite with three promising hit molecules identified among them, suggesting the hydroxyl group at C- $7^{\prime}$ in these alcohol analogues is contributing greatly to their antiplasmodial activity. Further exploration of the core structure using chemistry approaches and biological screening including in vivo studies in an animal model of malaria may yield important antimalarial leads.
\end{abstract}

Keywords: Resistance, Antiplasmodial, Piperidines, Cytotoxicity, Selectivity

\footnotetext{
*Correspondence: njutain.moses@ubuea.cm; smbuangalefange@gmail.com

'Biotechnology Unit and Department of Biochemistry and Molecular Biology,

Faculty of Science, University of Buea, Buea, Cameroon

${ }^{3}$ Department of Chemistry, Faculty of Science, University of Buea, Buea,

Cameroon

Full list of author information is available at the end of the article
}

(c) The Author(s). 2018 Open Access This article is distributed under the terms of the Creative Commons Attribution 4.0 International License (http://creativecommons.org/licenses/by/4.0/), which permits unrestricted use, distribution, and reproduction in any medium, provided you give appropriate credit to the original author(s) and the source, provide a link to the Creative Commons license, and indicate if changes were made. The Creative Commons Public Domain Dedication waiver (http://creativecommons.org/publicdomain/zero/1.0/) applies to the data made available in this article, unless otherwise stated. 


\section{Background}

Parasite resistance in chemotherapy of clinical malaria is a major threat to treatment outcome. The antimalarials frequently used include the 4-aminoquinolines, arylamino alcohols, antifolates and the artemisinins in various formulations. Artemisinin-based combination therapies (ACTs) along with other control tools have greatly reduced malaria morbidity and mortality in the last decade [1]. There is increasing resistance to the other drug classes cited above while delayed parasite clearance to the artemisinins has been detected in five countries of the Greater Mekong, in Southeast Asia along with multi-drug resistance in $P$. falciparum. In this area delayed parasite clearance has also been reported for ACTs where there is resistance to the partner drug and it is thought that artemisinin could facilitate selection for resistance to the partner drug $[2,3]$.

The approaches presently used to discover new antimalarials include screening of synthetic molecules generated using medicinal chemistry and natural products from plants, chemical modification of existing antimalarials, development of hybrid molecules with a combination of suitable pharmacochemical properties; testing of commercially available drugs approved for treatment of other human diseases and molecular modelling using virtual screening technology and docking $[4,5]$. Methods presently employed in compound screening include high-throughput screens of large compound libraries in phenotypic (whole- cell) or target assays. Whole cell screens are done on blood, liver and transmission stages of the parasite [4].

The piperidines constitute a very large chemical class of both natural and synthetic compounds containing the six membered heterocyclic nucleus [6]. The nucleus is present in many naturally occurring alkaloids [7]. This nucleus confers significant biological properties hence the compounds are of tremendous importance in medicinal chemistry. Extensive synthetic exploration of piperidine-containing molecules has yielded very diverse structural analogues with wide ranging and interesting pharmacological activities [8]. Piperdine is one of the most common heterocycles found in pharmaceutical agents, typically as a linker or to improve the drug's pharmacokinetic profile [9]. Hence the pharmacological spectrum of the analogues include anti-allergic, anti-inflammatory, analgesic, antioxidant, anti-psychotic, antidepressant, anti-diabetic, anticancer, antibacterial, antimalarial, antifungal and other activities with a considerable number of compounds in clinical use [10, 11].

In a previous communication, we reported the synthesis of a series of 1,4-disubstituted piperidines. When tested, these compounds displayed high affinity for sigma receptors. In a bid to further explore the pharmacological potential of these compounds and in view of the wide range of biological activities reported for substituted piperidines, these 1, 4-piperidines were also screened for antiplasmodial activity as part of our continuing search for efficacious antimalarials [12].

\section{Methods}

\section{Synthetic piperidines}

The synthesis of the 14 piperidines has been described in detail [12]. The compounds are based on a common parent skeleton shown in Fig. 1 with substituents at the C4 and $\mathrm{N} 1$ positions of the piperidyl parent fragment. The compounds can be grouped into three chemical classes based on the functional groups present in these substituents: ketones (1-6), alcohols (7-12) and amines $(\mathbf{1 3}, \mathbf{1 4})$. For the bioassay all compounds were tested in the hydrochloride form. The ketones: [1-(4-fluorobenzyl) piperidin-4-yl] [4-fluorophenyl] methanone (1), [1-(3, 4-dichlorobenzyl) piperidin-4-yl] [4-fluorophenyl] methanone (2), [1-(4-chlorobenzyl) piperidin-4-yl] [4-fluorophenyl] methanone (3), [1-(2-nitrobenzyl) piperidin-4-yl] [4-fluorophenyl] methanone (4), [1-(4-bromobenzyl) piperidin-4-yl] [4-fluorophenyl] methanone (5), [1-(4-methylbenzyl) piperidin-4-yl] [4-fluorophenyl] methanone (6); methanol analogues: [1-(4-fluorobenzyl) piperidin-4-yl] [4-fluorophenyl] methanol (7), [1-(3, 4-dichlorobenzyl) piperidin-4-yl] [4- fluorophenyl] methanol (8), [1-(4-chlorobenzyl) piperidin-4-yl] [4-fluorophenyl] methanol (33c) (9), [1-(2-nitrobenzyl) piperidin-4-yl] [4- fluorophenyl] methanol (10), [1-(4-bromobenzyl) piperidin-4-yl] [4- fluorophenyl] methanol (11), [1-(4-methylbenzyl) piperidin-4-yl] [4- fluorophenyl] methanol (12); and two bromobenzylamine analogues: $\mathrm{N}$ -\{[1-(2-nitrorobenzyl) piperidin-4-yl] [4-fluorophenyl] methyl $\}$-3-bromobenzylamine (13) and $\mathrm{N}-\{[1-(4-$-bromo

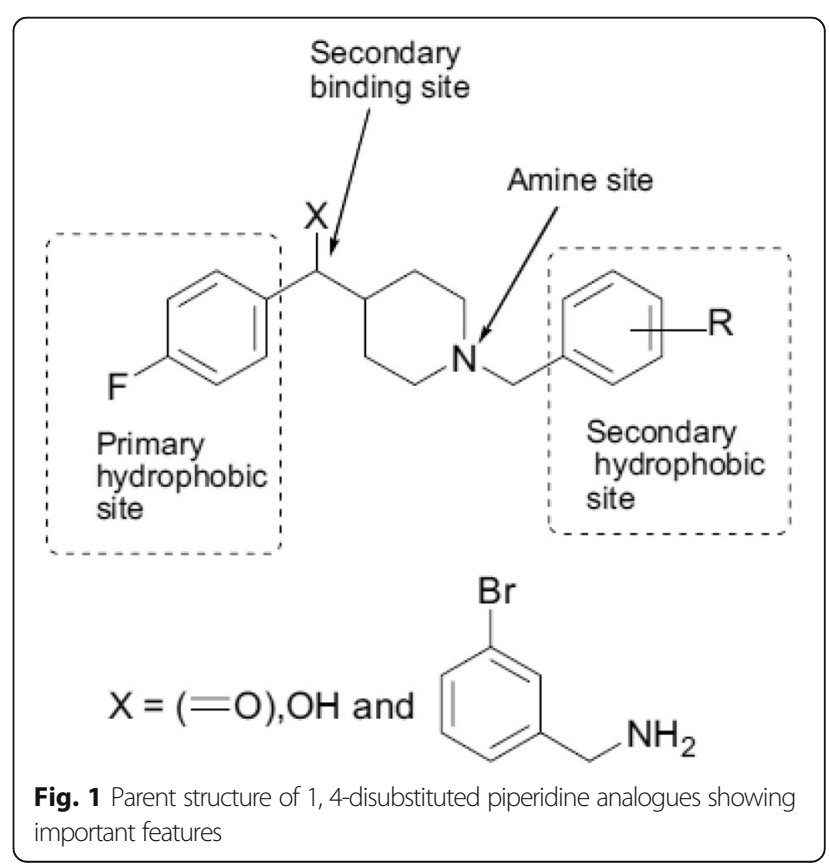


benzyl) piperidin-4-yl] [4-fluorophenyl] methyl\}-3-bromobenzylamine (14).

\section{In vitro growth inhibition assay}

Two Plasmodium falciparum parasite strains were obtained from MR4 (Manassas, Virginia, USA) and stored in liquid nitrogen. The 3D7 (MRA-102) strain is chloroquine- sensitive while $\mathrm{Dd} 2$ is a multidrug resistant clone of the W2 strain with resistance to chloroquine, quinine, mefloquine, sulfadoxine and pyrimethamine. Parasite stocks were thawed, grown and maintained in continuous culture by the candle jar technique with some modifications $[13,14]$. The culture consisted of $4 \%$ hematocrit suspension of human O+ erythrocytes in RPMI-1640 medium (10.43 g/L supplemented with $0.01 \mathrm{mg} / \mathrm{mL}$ gentamycin, $25 \mathrm{mM}$ Hepes buffer, $25 \mathrm{mM} \mathrm{NaHCO}$ ) and $5 \mathrm{~g}$ Albumax II. All culture reagents were obtained from Sigma-Aldrich Inc. (Germany) except for Albumax II (Gibco; Invitrogen, USA). Cultures were incubated at $37{ }^{\circ} \mathrm{C}$ in $5 \% \mathrm{CO}_{2}$.

A primary screen for antiplasmodial activity at a single concentration was performed against $\mathrm{Dd} 2$ as described with some modifications [15], to identify active compounds. Stock solutions of compound $(1 \mathrm{mg} / \mathrm{mL})$ was initially dissolved in dimethylsulfoxide (DMSO), then gentamycin-free incomplete medium (without Albumax II) added giving $2 \%$ final DMSO; the solutions were sterilized and stored. The positive control solutions (artemether and quinine at $5 \mu \mathrm{g} / \mathrm{mL}$ ) were prepared similarly. The compounds were tested at a final concentration of $40 \mu \mathrm{g} / \mathrm{mL}$ in duplicate in a 96 well microtitre plate (100 $\mu \mathrm{L}$ per well), followed by $100 \mu \mathrm{L}$ of $1 \%$ parasitized blood. Positive and negative controls (no drug) were included. The plate was incubated under the same culture conditions as above for $48 \mathrm{~h}$ and antiplasmodial activity determined by fluorescence microscopy (Leitz Wetzlar, Germany) with acridine orange stain at $\times 40$ magnification under oil immersion [14]. The number of infected erythrocytes $(E i)$ was counted in 20 monolayer fields (approximately 1500 cells per field) and the percentage parasitaemia was calculated using the formula:

$$
\% \text { parasitaemia }=\frac{\sum E_{i}}{30,000} \times 100
$$

The percentage inhibition per concentration was then obtained using the formula below:

$$
\begin{aligned}
& \text { percentage (\%) inhibition } \\
& =\frac{\% \text { parasitaemia of control well-\%parasitaemia of test well }}{\% \text { parasitaemia of control well }} \\
& \quad \times 100 \%
\end{aligned}
$$

A secondary screen was performed as above for compounds that showed greater than $50 \%$ inhibition in the primary screen at final concentrations from 0.625$40 \mu \mathrm{g} / \mathrm{mL}$ in order to determine the $\mathrm{IC}_{50}$ and $\mathrm{IC}_{90}$ values on $3 \mathrm{D} 7$ and $\mathrm{Dd} 2$ strains; $\mathrm{IC}_{50}$ values of controls were also determined similarly. After incubation the plate was frozen at $-20{ }^{\circ} \mathrm{C}$ for the parasite lactate dehydrogenase (pLDH) assay.

\section{Parasite growth quantification by lactate dehydrogenase assay}

The reagent preparation and assay were done as described [16]. The plates were subjected to 3 freeze-thaw cycles to haemolyze the red blood cells. One hundred microlitre $(100 \mu \mathrm{L})$ of Malstat reagent was added to each required well of a fresh microtitre plate followed by $20 \mu \mathrm{L}$ of culture. Then $25 \mu \mathrm{L}$ of nitroblue tetrazolium/ phenazine ethosulfate (NBT/PES) solution was added initiating the reaction. The plates were then incubated for an hour in the dark and optical density (OD) measured at $650 \mathrm{~nm}$ (Emax-Molecular Devices Corporation, California, USA).

\section{Cytotoxicity test}

This was done on monkey kidney epithelial cells, LLC-MK2, (ATCC, USA) as described [17] except for use of same culture medium and conditions for $P$ falciparum above. The cells, 10,000 in $100 \mu \mathrm{L}$ medium per well, were cultured for $24 \mathrm{~h}$ to become confluent and attached to the bottom of the well and the medium replaced with $100 \mu \mathrm{L}$ of fresh medium. Solutions of 9 compounds $(1000 \mu \mathrm{g} / \mathrm{mL})$ which showed moderate to high antiplasmodial activity, prepared same as in the primary screen above, were serially diluted with medium and added in duplicate wells to final concentrations of 7.8 to $500 \mu \mathrm{g} / \mathrm{mL}$. A negative control without test substance was included. The plates were incubated for $72 \mathrm{~h}$ at $37^{\circ} \mathrm{C}$ in $5 \% \mathrm{CO}_{2}$ and cell viability were determined using microscopy to observe dead cells which appeared dark and deformed. This was followed by the MTT/formazan assay as described above with slight modification [17]. The $\mathrm{CC}_{50}$ values (50\% cytotoxic concentration) for each compound was obtained using Microsoft excel 2007. The selectivity index $(S I)$ was calculated using the formula:

$$
S I=\frac{\mathrm{CC}_{50} \text { on LLC-MK2 cells }}{\mathrm{IC}_{50} \text { on P.falciparum }}
$$

\section{Data analysis}

For the parasite lactate dehydrogenase assay, the background OD of blank wells containing non parasitized red blood cells was subtracted from values of all test wells. OD values from control wells void of test compound represented the maximum $\mathrm{pLDH}$ activity. The 
OD values obtained were used to determine the $\mathrm{IC}_{50}$, and $\mathrm{IC}_{90}$ values using the software IC Method IC Estimator V1.2 [18], an online calculator of IC values. Each assay was done twice in duplicates and the $4 \mathrm{IC}_{50}$ or $\mathrm{CC}_{50}$ values obtained were pooled together and expressed as mean IC \pm S.D.

\section{Results}

\section{Antiplasmodial activity of piperidines}

Screening for antiplasmodial activity involved a two-stage process, primary and secondary. Only compounds that displayed greater than $50 \%$ inhibition of $P$. falciparum growth in the primary screen progressed to the secondary assay. In the current study, 13 out of 14 compounds met this criterion while one compound, 4, displayed poor inhibition of $P$. falciparum growth (Table 1) and was eliminated from further screening. In the secondary assay, the following criteria were adopted for antiplasmodial activity: active, $\mathrm{IC}_{50}<5 \mu \mathrm{g} / \mathrm{mL}$; moderately active: $5 \mu \mathrm{g} / \mathrm{mL} \leq \mathrm{IC}_{50} \leq 10 \mu \mathrm{g} / \mathrm{mL}$; weakly active: $\mathrm{IC}_{50} \geq 10 \mu \mathrm{g} / \mathrm{mL}$. All 13 compounds displayed dose dependent activity on both the 3D7 and Dd2 strains. For most of the compounds, the $\mathrm{IC}_{50}$ values were comparable between the chloroquine-sensitive 3D7 and -resistant $\mathrm{Dd} 2$ strains, spanning a range of $\mathrm{IC}_{50}$ values between 1.03 and $14.51 \mu \mathrm{g} / \mathrm{mL}$ (Table 2). Consequently, the rank orders of potency were fairly similar between the two strains. On the 3D7 strain, eight compounds $(\mathbf{2}, \mathbf{3}, \mathbf{7}, \mathbf{8}$, $9,11,12,14)$ emerged as active, while two $(1,13)$ were moderately active and three $(\mathbf{5}, \mathbf{6}, \mathbf{1 0})$ were classified as weakly active. On the Dd2, seven compounds (3, 7, 8, 9, $11,12,14)$ emerged as active while there were three each in the moderately active $(\mathbf{1}, \mathbf{2}, \mathbf{1 3})$ and weakly

Table 1 Inhibition of $P$. falciparum Dd2 growth by piperidine analogues at $40 \mu \mathrm{g} / \mathrm{mL}$

\begin{tabular}{|c|c|c|c|}
\hline Chemical class & Code & Substituent & Inhibition (\%) \\
\hline \multirow[t]{6}{*}{ Ketones } & 1 & $4^{\prime \prime}-\mathrm{F}$ & 83.2 \\
\hline & 2 & $3^{\prime \prime}, 4^{\prime \prime}-\mathrm{Cl}_{2}$ & 82.7 \\
\hline & 3 & $4 "-\mathrm{Cl}$ & 56.6 \\
\hline & 4 & $2 "-\mathrm{NO}_{2}$ & 27.7 \\
\hline & 5 & $4 "-B r$ & 64.8 \\
\hline & 6 & 4"-Me & 59.1 \\
\hline \multirow[t]{6}{*}{ Alcohols } & 7 & $4^{\prime \prime}-\mathrm{F}$ & 81.3 \\
\hline & 8 & $3^{\prime \prime}, 4^{\prime \prime}-\mathrm{Cl}_{2}$ & 81.7 \\
\hline & 9 & $4^{\prime \prime}-\mathrm{Cl}$ & 93.2 \\
\hline & 10 & $2^{\prime \prime}-\mathrm{NO}_{2}$ & 79.7 \\
\hline & 11 & $4^{\prime \prime}-\mathrm{Br}$ & 85.6 \\
\hline & 12 & 4"-Me & 83.1 \\
\hline \multirow[t]{2}{*}{ Amines } & 13 & $2 "-\mathrm{NO}_{2}$ & 72.9 \\
\hline & 14 & $4^{\prime \prime}-\mathrm{Br}$ & 86.0 \\
\hline
\end{tabular}

$\operatorname{Dd} 2$ is a chloroquine-resistant $P$. falciparum strain
Table 2 Antiplasmodial activity of 1, 4-disubstituted piperidines on P. falciparum 3D7 and Dd2 strains

\begin{tabular}{|c|c|c|c|c|}
\hline \multirow{3}{*}{$\begin{array}{l}\text { Compound } \\
\text { code }\end{array}$} & \multicolumn{4}{|c|}{ IC values $(\mu \mathrm{g} / \mathrm{mL})$} \\
\hline & \multicolumn{2}{|l|}{$3 \mathrm{D} 7$} & \multicolumn{2}{|l|}{ Dd2 } \\
\hline & $\mathrm{IC}_{50}$ & $\mathrm{IC}_{90}$ & $\mathrm{IC}_{50}$ & $I_{90}$ \\
\hline 1 & $8.45 \pm 2.11$ & $17.85 \pm 0.18$ & $5.69 \pm 2.38$ & $27.59 \pm 0.78$ \\
\hline 2 & $4.30 \pm 3.75$ & $17.61 \pm 0.06$ & $5.97 \pm 0.02$ & $24.86 \pm 4.14$ \\
\hline 3 & $3.21 \pm 0.21$ & $17.9 \pm 2.39$ & $4.12 \pm 1.28$ & $32.38 \pm 0.67$ \\
\hline 4 & ND & ND & ND & ND \\
\hline 5 & $10.02 \pm 0.30$ & $17.23 \pm 0.97$ & $14.51 \pm 1.34$ & $32.31 \pm 4.17$ \\
\hline 6 & $13.63 \pm 0.31$ & $19.08 \pm 2.46$ & $12.75 \pm 3.21$ & $37.15 \pm 0.53$ \\
\hline 7 & $4.00 \pm 0.67$ & $14.61 \pm 1.52$ & ${ }^{\mathrm{a}} 2.52 \pm 0.77$ & $17.71 \pm 4.34$ \\
\hline 8 & $4.43 \pm 0.32$ & $13.89 \pm 1.25$ & ${ }^{\mathrm{a}} 1.30 \pm 0.47$ & $17.33 \pm 3.27$ \\
\hline 9 & $1.53 \pm 0.24$ & $16.08 \pm 2.13$ & $1.67 \pm 0.24$ & $16.08 \pm 2.13$ \\
\hline 10 & $13.54 \pm 0.54$ & $19.11 \pm 0.02$ & $13.98 \pm 1.76$ & $35.28 \pm 2.02$ \\
\hline 11 & $2.51 \pm 0.30$ & $16.80 \pm 0.88$ & ${ }^{\mathrm{a}} 1.03 \pm 0.124$ & $27.82 \pm 0.98$ \\
\hline 12 & $3.37 \pm 0.82$ & $15.74 \pm 0.00$ & $2.78 \pm 0.09$ & $10.2 \pm 3.31$ \\
\hline 13 & $5.88 \pm 2.49$ & $8.94 \pm 2.50$ & $5.38 \pm 0.69$ & $25.93 \pm 2.83$ \\
\hline 14 & $2.28 \pm 0.64$ & $11.31 \pm 3.50$ & $2.57 \pm 1.64$ & $16.21 \pm 0.35$ \\
\hline Art & 0.045 & - & $0.039 \pm 0.00$ & $0.046 \pm 0.00$ \\
\hline QN & 0.171 & - & 0.127 & - \\
\hline
\end{tabular}

3D7 is a chloroquine-sensitive $P$. falciparum strain. -Not done, Art artemether, QN quinine. ND not determined due to low activity in the primary screen. Chemical classes of compounds:- carbonyls:1-6; alcohols: 7-12, and amines: 13-14. ${ }^{a}$ Compounds more active on chloroquine-resistant Dd2 than 3D7

active $(5,6,10)$ groups. Compounds 9 and 11 displayed the highest activities against both $P$. falciparum strains, with $\mathrm{IC}_{50}$ values of $1.53 \mu \mathrm{g} / \mathrm{mL}$ and $1.03 \mu \mathrm{g} / \mathrm{ml}$, respectively, but these compounds were about one order of magnitude less potent than quinine. Three compounds $(7,8,11)$ were particularly noteworthy because they were more potent on the chloroquine-resistant $\operatorname{Dd} 2$ strain than the drug-sensitive 3D7 strain, suggesting they could serve as useful leads for the discovery of new antimalarials.

\section{Cytotoxicity of piperidines}

The 10 compounds which showed moderate to high activity also recorded high $\mathrm{CC}_{50}$ values ranging from 62 to $375 \mu \mathrm{g} / \mathrm{mL}$ i.e. from 2 to 12 times above the cut-off point for cytotoxicity of $30 \mu \mathrm{g} / \mathrm{mL}$ [19] suggesting the more active compounds are non-cytotoxic. For 3D7, compounds 3 and $\mathbf{1 4}$ had the lowest and highest $S I$ values of 19 and 163 respectively while for Dd2 compound $\mathbf{3}$ and $\mathbf{1 1}$ had the lowest and highest values of 15 and 183 respectively (Table 3). The mean SI values for both strains ranged from 17 to 156 .

\section{Discussion}

No new chemical class of antimalarials has been introduced to clinical practice since 2006 [20] whereas 
Table $3 \mathrm{CC}_{50} \mathrm{~S}$ and selectivity indices of piperidine analogues on LLC-MK2 monkey kidney epithelial cells

\begin{tabular}{lllll}
\hline Compound code $^{\mathrm{a}}$ & $\mathrm{CC}_{50}(\mu \mathrm{g} / \mathrm{mL})$ & SI on 3D7 & SI on Dd2 & Mean SI \\
\hline 1 & 187.5 & 22.17 & 32.91 & $27.54 \pm 7.59$ \\
2 & 187.5 & 43.51 & 31.37 & $37.44 \pm 8.58$ \\
3 & 62.5 & 19.45 & 15.16 & $17.31 \pm 3.0$ \\
7 & 375 & 93.67 & 148.34 & $121.01 \pm 38.7$ \\
8 & 93.75 & 21.14 & 71.67 & $46.41 \pm 35.7$ \\
9 & 250 & 149.52 & 162.97 & $156.25 \pm 9.5$ \\
11 & 187.5 & 74.49 & 182.03 & $128.26 \pm 76.1$ \\
12 & 187.5 & 55.52 & 67.39 & $61.46 \pm 8.39$ \\
13 & 375 & 63.71 & 69.70 & $66.71 \pm 4.24$ \\
\hline
\end{tabular}

Chemical classes of compounds:- ketones: 1-3 and alcohols: 7-12. ${ }^{\text {a }}$ Compounds 4, 5, $\mathbf{6}$ and $\mathbf{1 0}$ not tested for cytotoxicity due to low activity in either the primary screen $(<50 \%$ inhibition) and or the secondary screen $\left(\mid C_{50}>10 \mu \mathrm{g} / \mathrm{mL}\right.$ ). Classification of cytotoxicity: $\mathrm{CC}_{50}<1 \mu \mathrm{g} / \mathrm{mL}$ (high cytotoxicity), $\mathrm{CC}_{50} 1 \mu \mathrm{g} / \mathrm{mL}-10 \mu \mathrm{g} / \mathrm{mL}$ (moderate cytotoxicity), $\mathrm{CC}_{50} 10 \mu \mathrm{g} / \mathrm{mL}$ $30 \mu \mathrm{g} / \mathrm{mL}$ (mild cytotoxicity) and $\mathrm{CC}_{50}>30 \mu \mathrm{g} / \mathrm{mL}$ (no observable cytotoxicity) [25]. Selectivity Index (SI) $=\mathrm{CC}_{50}$ on LLC-MK2 cells// $\mathrm{C}_{50}$ on P. falciparum. Mean SI: geometric mean of the Selectivity Indices of the 3D7 and Dd2 parasite strains. Cut-off point for selectivity: $\mathrm{SI}>10$ (non-toxic); $\mathrm{SI} \leq 10$ (toxic) [20]

presently there is a threat of emergence of resistance to artemisinins with delayed parasite clearance by some ACTs, the last efficacious therapeutics approved for use against malaria [3]. Hence the need to discover and develop new efficacious molecules remains an active area of research. In this study, three 1, 4-disubstituted piperidines $(7,8,11)$ all alcohols, were identified which were more active on the resistant $\mathrm{Dd} 2$ strain with lower $\mathrm{IC}_{50} \mathrm{~S}$ than on the 3D7 strain; these analogues also showed very high selectivity for the parasite with $S I$ values ranging from about 21 to 182 . These findings demonstrate the potential of these piperidines as candidate antimalarial leads.

In the primary screen at a fixed concentration of $40 \mu \mathrm{g} / \mathrm{mL}$, nine $(60 \%)$ of the 14 piperidines produced over $80 \%$ inhibition (Table 1). This high proportion of compounds with fairly high activity is a good preliminary indication of the antiplasmodial bioactivity in the piperidine parent structure. Screening at a single concentration likely to show activity is a useful strategy which identifies active compounds early in the drug discovery pipeline, albeit in vitro in this case. This eliminates wasteful extensive screening of compounds of low interest. In the secondary screen, eight of the nine compounds showed high antiplasmodial activity. Seven of these eight compounds also showed high activity in both the two screens showing consistency in the results of the two experiments, further confirming their potential as candidate antimalarial leads. The promising analogues $(7,8,11)$ identified in this work qualify for further investigation in vivo in an animal model of malaria. These compounds may be classified as antiplasmodial hits based on their high selectivity for the parasite over the mammalian cell. Their $\mathrm{CC}_{50}$ and $\mathrm{SI}$ values are far above the cut -off values for cytotoxicity of $30 \mu \mathrm{g} / \mathrm{mL}$ [19] and $S I>10$ respectively [20] as shown on Table 3 . These high $S I$ values indicate very low risk of toxicity to mammalian cells. This high safety margin is not unexpected as several piperidine derivatives are being used clinically for various diseases [9], although toxicity depends on molecular structure.

Considering the activity of the compounds with respect to the present data, one can find active compounds in each of the three chemical classes i.e. ketones $(2,3)$, alcohols $(7,8,9,11,12)$ and amine $(14)$. Overall alcohols exhibited the highest activity (among which are the hits) in the primary and secondary screens, the single most active and most selective compound on the resistant strain being a methanol analogue (11). The high activity recorded across the three chemical classes suggests that the activity is accounted for largely by the common core structure, the activity of which is modified by the substituent groups shown on Table 1 .

The high activity of the alcohols suggests the hydroxyl

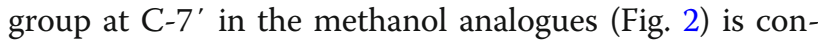
tributing greatly to the activity of these analogues. Also, the methanol analogues were the least cytotoxic as seen from their relatively higher SI values (Table 3). These compounds were designed as 1, 4-disubstituted piperidine analogues inspired by spipethiane, a molecule with a restricted conformation due to spirofusion in its structure and is selective for sigma-1 receptors which elicit diverse biological effects [12]. Given the presence of a piperidyl fragment in spipethiane, the latter may well turn out to be an antiplasmodial agent. The high activity displayed by these compounds supports previous reports in literature. A chemical series of 44 synthetic 1-phenethyl-4-aminopiperidine derivatives screened against $P$. falciparum $\mathrm{K} 1$ resistant strain demonstrated very high antiplasmodial activity; 33 of these compounds had $\mathrm{IC}_{50}$ values less than $5 \mu \mathrm{g} / \mathrm{mL}$ with 13 of them between $0.17 \mu \mathrm{g} / \mathrm{mL}$ and $0.91 \mu \mathrm{g} / \mathrm{mL}$. These compounds were equally fairly selective for the parasites [21]. Several substituted piperidines display a wide range of biological activities like antiviral, antidepressants, cytotoxicity and antimalarial [22]. Also high antiplasmodial activity has been observed in plant derived piperidines e.g. febrifugine isolated from the roots of Dichroa febrifuga. Synthetic analogues of febrifugine devoid of the piperidine ring showed decreased antiplasmodial activity suggesting that the activity of febrifugine and its analogues is partly due to the piperidine ring [23]. The same finding was recorded following conversion of some natural piperidines isolated from Senna spectabilis to semisynthetic derivatives lacking the piperidine core [24], further illustrating the significant contribution of this core to bioactivity of molecules which posses it. 


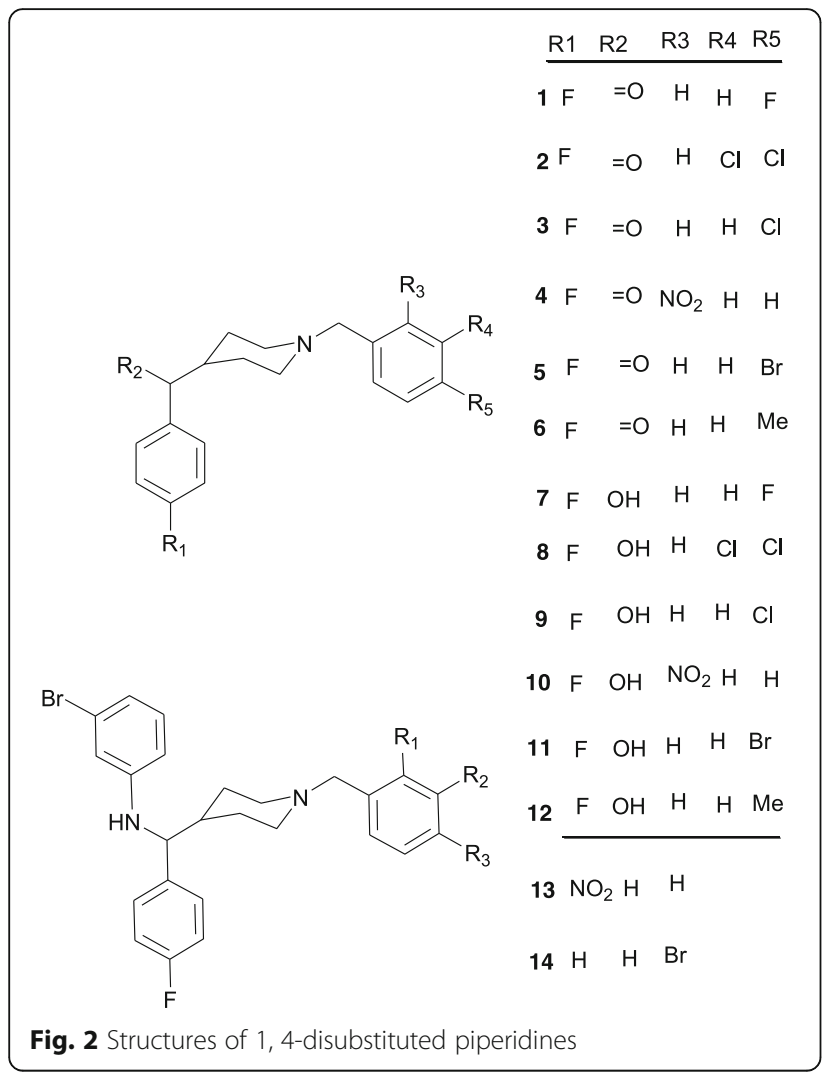

\section{Conclusions}

Based on the antiplasmodial activity and selectivity indices, three antiplasmodial hits have been identified from the 14 synthetic piperidines screened. The activity of the 1, 4-disubstituted piperidine structure is modulated by the substituent groups particularly the hydroxyl group at C-7' in the methanol analogues. These findings demonstrate the potential of these synthetic piperidine analogues as candidate antimalarial leads, justifying further exploration using chemistry approaches and biological screening with in vivo studies in an animal model of malaria which may yield efficacious and safe antimalarial leads.

\section{Abbreviations}

$\mathrm{ACT}$ : Artemisinin based combination therapy; $\mathrm{CC}_{50}$ : Cytotoxic concentration for $50 \%$ of population of cells; $I_{50}$ : Inhibitory concentration for $50 \%$ of population of cells; MTT: Tetrazolium; NBT: Nitroblue tetrazolium; PES: Phenazine ethosulfate; pLDH: Parasite lactate dehydrogenase; SI: Selectivity index

\section{Acknowledgements}

The Biotechnology Unit in the Faculty of Science, University of Buea, provided facilities for the bioassays while the chemistry work was carried out in the Department of Chemistry of the University.

\section{Funding}

Funds for this work were provided from the budget of the University of Buea, Cameroon.

\section{Availability of data and materials}

The datasets used and/or analysed during the current study are available from the corresponding author on reasonable request.

\section{Authors' contributions}

MNN designed the biological experiments and drafted the manuscript, GNA ran the biological experiments, DZ directed the bench bioassays and analyzed the data. HNI performed the chemical synthesis, FNK contributed to the study design and drafting the manuscript, and SMNE designed and supervised the chemistry work. All authors contributed to writing the manuscript and approved the final version.

\section{Ethics approval and consent to participate}

Not applicable.

\section{Consent for publication}

Not applicable.

\section{Competing interests}

The authors declare that they have no competing interests.

\section{Publisher's Note}

Springer Nature remains neutral with regard to jurisdictional claims in published maps and institutional affiliations.

\section{Author details}

${ }^{1}$ Biotechnology Unit and Department of Biochemistry and Molecular Biology, Faculty of Science, University of Buea, Buea, Cameroon. ${ }^{2}$ Department of Biochemistry and Molecular Biology, Faculty of Science, University of Buea, Buea, Cameroon. ${ }^{3}$ Department of Chemistry, Faculty of Science, University of Buea, Buea, Cameroon.

Received: 10 July 2017 Accepted: 25 June 2018

Published online: 04 July 2018

\section{References}

1. World Health organization: World Malaria Report 2016. http://www.who. int/malaria/publications/world-malaria-report-2015/report/en/. Accessed 20 Jan 2016.

2. Parija SC, Praharaj I. Drug resistance in malaria. Indian J Med Microbiol. 2011; 29:243-8.

3. World Health Organization: Global Malaria Programme. 2015. In: Status report on artemisinin and ACT resistance, WHO/HTM/GMP/2015.4. 2015. www.who.int/malaria/publications/atoz/status-rep-artemisinin-resistancesept2015.pdf Accessed 20 Jan 2016.

4. Flannery EL, Chatterjee AK, Winzeler EA. Antimalarial drug discovery: approaches and progress towards new medicines. Nat Rev Microbiol. 2013; 11:849-62.

5. Aguiar ACC, da Rocha EMM, de Souza NB, França TCC, Krettli AU. New approaches in antimalarial drug discovery and development - a review. Mem Inst Oswaldo Cruz. 2012:107:831-45.

6. PubChem. Open Chemistry Database. Piperidine. https://pubchem.ncbi.nlm. nih.gov/compound/piperidine. Accessed 29 June, 2017.

7. Kaur R, Arora S. Alkaloids-important therapeutic secondary metabolites of plant origin. J Crit Rev. 2015;2:1-8.

8. Haider S, Saify ZS, Begum N, Ashraf S, Zarreen T, Saeed SMG. Emerging pharmaceutical applications of piperidine, pyrrolidine and its derivatives. World J Pharm Res. 2014:3:987-1024.

9. Baumann M, Baxendale IR. An overview of the synthetic routes to the best selling drugs containing 6-membered heterocycles. Beilstein J Org Chem. 2013;9:2265-319.

10. Ahmed A, Molvi Kl, Nazim S, Baig I, Memon T, Rahil M. The importance of six membered saturated nitrogen containing ring in psychological disorders. J Chem Pharm Res. 2012;4:872-80.

11. Pati B, Banerjee S. Importance of piperidine moiety in medicinal chemistry research: a review. J Pharm Res. 2012;5:5493-509.

12. Ikome HN, Ntie-Kang F, Ngemenya MN, Tu Z, Mach RH, Efange SMN. 4aroylpiperidines and 4-(a-hydroxyphenyl) piperidines as selective sigma-1 receptor ligands: synthesis, preliminary pharmacological evaluation and computational studies. Chem Cent J. 2016;10:53.

13. Trager $W$, Jensen JB. Human malaria parasites in continuous culture. Science. 1976;193:673-5.

14. Moll K, Ljungstrom I, Perlmann H, Scherf A, Wahlgren M. Methods in malaria research. 6th ed. Manassas: MR4/ATCC; 2013. 
15. Ngemenya MN, Metuge HM, Mbah JA, Zofou D, Babiaka SB, Titanji VPK. Isolation of natural product hits from Peperomia species with synergistic activity against resistant Plasmodium falciparum strains. European J Med Plants. 2015:5:77-87.

16. Zofou D, Tene M, Ngemenya MN, Tane P, Titanji VPK. In vitro antiplasmodial activity and cytotoxicity of extracts of selected medicinal plants used by traditional healers of western Cameroon. Malar Res Treat. 2011;2011:6. https://doi.org/10.4061/2011/561342.

17. Nondo RSO, Moshi MJ, Erasto P, Zofou D, Njouendou AJ, Wanji S, Ngemenya MN, Kidukuli AW, Masimba PJ, Titanji VPK. Evaluation of the cytotoxic activity of extracts from medicinal plants used for the treatment of malaria in Kagera and Lindi regions, Tanzania. J App Pharm Sci. 2015;5:007-12.

18. IC Method IC Estimator V1.2. http://www.antimalarial-icestimator.net/ Method.htm. Accessed 29 June 2018.

19. Malebo HM, Tanja W, Caletal M, Omolo MO, Hassanali A. Antiplasmodial, antitrypanosomal, antileshmanial and cytotoxicity activity of selected Tanzanian medicinal plants. Tanzan J Health Res. 2009;11:226-34.

20. Viau CM, Moura DJ, Facundo VA, Saffi J. The natural triterpene $3 \beta, 6 \beta, 16 \beta-$ trihydroxy-lup-20 (29)-ene obtained from the flowers of Combretum leprosum induces apoptosis in MCF-7 breast cancer cells. BMC Complement Altern Med. 2014;14:280.

21. Dardonville C, Fernandez-Fernandez C, Gibbon S, Jagerovic N, Nieto L, Gary R, Kaiser M, Reto B. Antiprotozoal activity of 1-phenethyl-4-aminopiperidine derivatives. Antimicrob Agents Chemother. 2009;53:3815-21.

22. Ravindran G, Muthusubramanian S, Perumal S. A convenient one pot synthesis of highly substituted piperidines through a Micheal addition aldol cyclization sequence. ARKIVOC. 2008;13:57-64.

23. Haruhisa K, Keisuki Y, Seiko H, Shingo H, Ryota K, Norimitsu H, Makoto M, Yoshiteru O. Exploration of a new type of antimalarial compounds based on febrifugine. J Med Chem. 2006;45:4698-706.

24. Pivatto M, Baccini LR, Sharma A, Nakabashi M, Danuello A, Júnior CV, Garcia CRS, Bolzani VS. Antimalarial activity of piperidine alkaloids from senna spectabilis and semisynthetic derivatives. J Braz Chem Soc. 2014;25:1900-6.

25. Faurant C. From bark to weed: the history of artemisinin. Parasite. 2011;18: 215-8.

\section{Ready to submit your research? Choose BMC and benefit from:}

- fast, convenient online submission

- thorough peer review by experienced researchers in your field

- rapid publication on acceptance

- support for research data, including large and complex data types

- gold Open Access which fosters wider collaboration and increased citations

- maximum visibility for your research: over $100 \mathrm{M}$ website views per year

At BMC, research is always in progress.

Learn more biomedcentral.com/submissions 